\title{
Clinico-epidemiological Profile of Patients with COVID-19 in a Tertiary Care Centre of Mid-Western Nepal
}

\author{
Shravya S Karki ${ }^{1}$, Pragya S Basnet ${ }^{2}$, Sauharda S Karki ${ }^{1}$, Basant Lamichhane ${ }^{2}$, \\ Damodar Sharma ${ }^{3}$, Birendra K Acharya ${ }^{3}$, Prahlad Karki ${ }^{4}$, Sunil KC ${ }^{4}$, Salman \\ Seikh$^{4}$, Santosh Kunwar ${ }^{4}$, Nishtha Rajbhandari ${ }^{1}$, Ujjwal MS Bhandari ${ }^{1}$, Sagar \\ Panthi ${ }^{2}$, Angelica Karki ${ }^{2}$, Jhankar Lamichhane ${ }^{2}$, Sangita Bhandary ${ }^{2}$
}

${ }^{1}$ Research Assistant,Rapti Academy of Health Sciences, Ghorahi, Dang, Nepal

${ }^{2}$ Hospital Administration,Rapti Academy of Health Sciences, Ghorahi, Dang, Nepal

${ }^{3}$ Department of Laboratory Medicine, Rapti Academy of Health Sciences, Ghorahi, Dang, Nepal

${ }^{4}$ Department of Internal Medicine, Rapti Academy of Health Sciences, Ghorahi, Dang, Nepal

\section{ABSTRACT}

Introduction: With little to no research done that sheds light on the COVID-19 pandemic in the Mid-Western region of Nepal, this study attempts to educate the general populace and concerned authorities on the impact of the pandemic in the region.

Materials and Methods: Patients presenting at Rapti Academy of Health Sciences between 14th May 2020 to December 21st 2020 diagnosed with COVID-19 were included in the study. These patients were reviewed for age, sex, address, recent travel history and presenting symptoms.

Results: A total of 3895 COVID -19 positive individuals were included in the study. The mean age of the patients was $33.6 \pm 13.8$ years, a majority $(49.5 \%)$ of the cases were in the $20-29$ years age group. $73.7 \%$ were male. $82.9 \%$ of the patients were from Dang, $86 \%$ of the cases of Dang were from urban areas, and the districts bordering India accounted for $88.5 \%$ of cases. Most of the positive patients were asymptomatic (97.1\%), Amongst the symptomatic cases, the most frequent clinical manifestation was both fever and cough. $8.5 \%$ of the patients also reported travel history, of which a majority had returned from India.

Conclusions: The patients were mostly young males belonging to the economically active age group who were mostly affected by COVID-19 in Mid-Western Nepal. It is important to carry out age-group targeted testing to flatten the infection curve. Testing must be done irrespective of observable symptoms to overcome this public health emergency.

Keywords: COVID-19; Clinico-demographic; SARS-CoV-2
Corresponding Author:

Shravya Singh Karki

Research Assistant,

Rapti Academy of Health Sciences, Ghorahi, Dang, Nepal ORCID ID:0000-0003-3908-0522

Email ID: shravskarki@gmail.com

Received: $19^{\text {th }}$ April 2021 Accepted: $15^{\text {th }}$ June 2021

Conflict of Interest: None Sources of Support: None

Citation: Karki SS, Basnet PS, Karki SS, LamichhaneB, Sharma D, Acharya BK, et al. Clinico-epidemiological Profile of Patients with COVID-19 in a Tertiary Care Centre of Mid-Western Nepal. NMJ 2021;4(1):429-32. DOI 10.3126/nmj.v4i1.36511 


\section{INTRODUCTION}

As of December 2020, there is no continent in the world that remains unscathed by the novel Coronavirus pandemic. The virus, which is believed to have been transmitted to humans through bats in the city of Wuhan in the Hubei Province of China was first detected in December 2019. ${ }^{1}$ While fairly new, the virus has proved to be one of the deadliest pandemics in human history, infecting over 79 million and claiming the lives of over 1.76 million over this past year. ${ }^{2}$ The virus is known to directly transmit among individuals through aerosol, faecal matter and the virus indirectly transmitted through fomites. ${ }^{3}$ The World Health Organization officially announced the COVID-19 disease caused by the SARS-CoV-2 to be a pandemic by $11^{\text {th }}$ March, $2020 .{ }^{4}$

While Majority of the population that have contracted the virus are asymptomatic, a significant portion of those infected experience mild symptoms such as fever, cough, headache, fatigue, and body ache. More severe symptoms include loss of one's ability to smell and taste, chest pain, difficulty in breathing and low oxygen saturation in the blood. The complications of COVID-19 include pneumonia, acute respiratory distress syndrome (ARDS), myocarditis, multi-organ failure, septic shock, and death. ${ }^{5}$

While every nation, including global superpowers such as the US and UK, are in shambles curbing the spread of the virus, Nepal has also been hit hard by the virus. While the first case of COVID-19 in Nepal was reported in mid-January, 2020 and ever since, over 250,000 individuals have been infected by the virus in Nepal while taking the lives of over $1,800 .^{6}$ The rapid spread of the virus has also affected districts in western Nepal located both in Karnali and Lumbini Provinces. (latest accessed 29/12/2020 ), Karnali province had 6,387 cases and 25 deaths while this number for Lumbini Province stood at 28,566 infections and 226 deaths. ${ }^{6}$

Dang, a district in Mid-Western Nepal, has a population of 548,151 and consists of two sub-metropolitan cities, and eight municipalities, of which one is an urban municipality and seven are rural municipalities. The district headquarters of Dang, Ghorahi, is the seventh-largest city in Nepal and the largest submetropolitan city of Nepal. As of $28^{\text {th }}$ December 2020, Dang has reported 3968 confirmed cases of COVID-19 and 35 deaths. $^{7}$

This study provides a clinico-demographic overview of the COVID-19 in several districts of Mid-Western Nepal. Using the testing data collected in Rapti Academy of Health Sciences, this study analyses the impact of demographic variables like age, sex, place of residence and travel history and clinical characteristics on COVID-19 patients. Out of the 29,656 tests conducted in the institute as of December $21^{\text {st }}, 2020$, there were a total of 3,985 positive cases, which is 13.4 percent of the tested population. There is an acute lack of clinico-demographic data related to COVID-19 in Midwestern Nepal and this study attempts to fill the void through empirical research in this field to better educate the general populace and all concerned authorities on the impact of the pandemic in the region.

\section{MATERIALS AND METHODS}

The study was designed as a cross-sectional study. The study was conducted at Rapti Academy of Health Sciences, Ghorahi, Dang, Nepal and all patients presenting at the Fever Clinic and samples sent from other fever clinics in the periphery, between $14^{\text {th }}$ May 2020 to December $21^{\text {st }} 2020$, diagnosed with COVID-19 were included in the study. For travel history, only cases presented between $14^{\text {th }}$ May 2020 and $21^{\text {st }}$ September 2020 were taken accounting for 1395 cases. Ethical approval for this study was taken from the Institutional Review Committee at Rapti Academy of Health Sciences. A detailed history of each patient's demographic variables, recent travel history, and presenting symptoms were recorded. The data was entered into a Microsoft Excel sheet and was statistically analysed using the same software.

\section{RESULTS}

There were 29,656 tests done at Rapti Academy of Health Sciences' RT-PCR laboratory, of which 3985 individuals tested positive, that is $13.4 \%$ tested positive for COVID-19. All of the 3985 cases were included in the study for analysis. The mean age of the patients was $33.6 \pm 13.8$ years, the median age is 31 , with an age range of two months to 90 years. The age group of 20-29 was the most affected age group accounting for $49.5 \%$ of the patients The majority of the cases found tended to be male sex with $73.7 \%(n=2938)$ of the cases and $26.3 \%(n=1047)$ female patient with 2.8 male to female ratio. The age group of 20-29 was the most affected age group accounting for $49.5 \%$ of the patients. (fig.1)

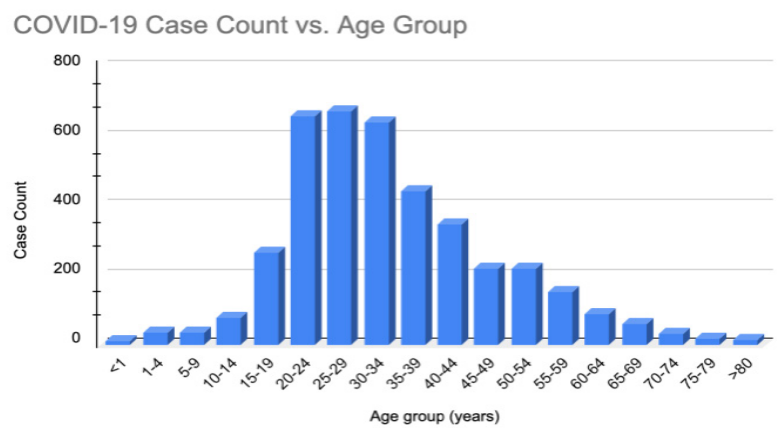

Figure 1: COVID-19 Case Count vs. Age Group

$82.9 \%$ of the total positive cases were from Dang District alone whereas 3\% of the cases hailed from Bardiya, 2.8\% from Pyuthan, $2.6 \%$ from Rolpa, 2.4\% from Salyan, 1.7\% from East Rukum, while the remaining $4.6 \%$ cases were from other neighbouring districts (which include Arghakhanchi, Banke, Kapilvastu, Rupandehi, Surkhet, West Rukum and other districts). Districts of Lumbini Province bordering India, i.e.,Banke, Bardiya, Dang, Kapilvastu, Rupandehi, Parasi accounted for $88.5 \%$ of the cases. Out of the total 3305 positive cases in the Dang district, 14\% $(n=433)$ of the positive cases were found to be in a rural setting whereas $86 \%(n=2656)$ of the positive cases were found to be in an urban setting.

Table 1 depicts number of COVID-19 positive cases within the various administrative subdivisions of Dang. In regard to Dang district, which shows a record of 3305 total positive cases, the administrative sub-division of Ghorahi Sub-Metropolitan City consisted of $47 \%(\mathrm{n}=1523)$, followed by Tulsipur SubMetropolitan City consisted of the $25.7 \%(n=833)$. 
NEPALESE MEDICAL JOURNAL issue 7 | vol 4 | 2021

Table 1: COVID-19 Case Count Within Dang by Administrative Subdivisions

\begin{tabular}{|c|c|c|c|c|c|}
\hline $\begin{array}{l}\text { Administrative Divisions of } \\
\text { Dang District }\end{array}$ & Case Count (3305) & Percentage $(\%)$ & $\begin{array}{l}\text { Administrative Divisions of } \\
\text { Dang District }\end{array}$ & Case Count (3305) & Percentage (\%) \\
\hline Babai Rural Municipality & 69 & 2.1 & Lamahi Municipality & 300 & 9.3 \\
\hline Bangalachuli Rural & & 5.5 & & & 1.4 \\
\hline Municipality & 178 & & Rajpur Rural Municipality & 45 & \\
\hline Dangisharan Rural & & 0.001 & & & 3.3 \\
\hline Municipality & 6 & & Rapti Rural Municipality & 108 & \\
\hline Gaduwa Rural Municipality & 87 & 2.7 & Shantinagar Rural Municipality & 93 & 2.9 \\
\hline Ghorahi Sub-Metropolitan City & 1523 & 47 & Tulsipur Sub-Metropolitan City & 833 & 25.7 \\
\hline
\end{tabular}

With regard to the presenting complaints, 97.1\% $(n=3868)$ of patients were reported to be asymptomatic at the time of swab collection in the Fever Clinic. Amongst the $117(2.9 \%)$ symptomatic cases, the most frequent manifestation was both fever and cough found in $90.6 \%$ of the patients followed by only fever in $0.9 \%$ of the patients, only cough in $5.1 \%$ Of the patients, diarrhoea in $0.9 \%$ Of the patients, headache in $0.9 \%$ of the patients and influenza-like illness (ILI) in $1.7 \%$ of the patients.

$8.5 \%(\mathrm{n}=1395)$ cases (between $14^{\text {th }}$ May 2020 and $21^{\text {st }}$ September 2020) also reported some form of recent travel history at the time of admission to the Fever Clinic, of which $72.3 \%$ of the patients had arrived from India, and $13.4 \%$ of the patients had arrived from the Middle East.

\section{DISCUSSION}

In this study, the clinico-epidemiological profile of COVID-19 patients tested at Rapti Academy of Health Sciences has been shown. Since there has been little to no research done that sheds light on the confluence of the pandemic in the region, this study attempts to educate the general populace and all concerned authorities on the impact of the pandemic in the region.

In this study, there was a male predominance of COVID-19, with a male to female ratio which is consistent with our finding, where we got a 2.8 times positivity rate in males from what was observed in female test-takers. A study on Racial and GenderBased Differences in COVID-19 conducted by Kopel et al. also showed a 73\% COVID-19 incidence in males. The authors came to the conclusion that the fatality rate was higher in men, possibly due to an increased prevalence of cardiopulmonary disease and smoking. ${ }^{8}$ Another study conducted by Bienvenu et al also concludes that the male sex is a risk factor for COVID-19.9 This proves that our findings were consistent with other contemporary studies.

With regards to the age group, young adults were most commonly affected by COVID-19 with the average age group being 20-29 years. This finding is consistent with other studies where the average age group was 20-29 years. Earlier studies have shown that in Nepal the highest number of COVID-19 cases was in the age group of 21 to 30 years, which on June 12, 2020, accounted for nearly $39 \%$ of the total cases in Nepal. ${ }^{10}$ A study conducted by Priya Venkatesan on the "Changing Demographics of COVID-19" also showed that in the later phases of the pandemic in the USA, between June 2020 to August 2020, the age group of 20-29, accounted for more than $20 \%$ of the total number of positive COVID-19 cases. Similarly in England, most cases between August 17 to 30 August 2020 were in individuals aged between 20-29 years of age. This could be because the younger age groups refrained from sticking to social distancing guidelines after a certain time, attending workplaces, universities and also due to better surveillance. ${ }^{11}$ A survey conducted by the Australian Department of Health also showed that the age group of 20-29 years had the highest incidence. ${ }^{12}$ A study conducted by Upadhyay et al. showed that age-targeted testing, with increased testing in the most proportionally affected age groups like the 15-40 age group was effective in showing marked flattening of the infection curve in India. ${ }^{13}$ Our findings show that the highest proportion of cases that is $34.2 \%$ of the cases belong to the 20-29 age group and are consistent with earlier studies. A possible reason for this could be because a large number of Nepali individuals belonging to the economically active age group of 20-29 years seek employment and education abroad, in India and the Middle East where the COVID-19 incidence is surging at an alarming rate.

A United Nations report published in July 2020 had shown that an estimated $90 \%$ of all reported COVID-19 cases belonged to urban areas, therefore becoming an epicentre for the pandemic. The size of their population and their higher level of global and local interconnectivity makes them more susceptible to spread the virus. ${ }^{14}$ Our findings are consistent with this report as $86 \%$ of the total cases in the Dang district were from urban settings like Urban Municipalities and Sub-Metropolitan Cities.

In regard to the clinical presentation of the COVID-19 patients, a study conducted by Henegan et al named "COVID-19: What proportion are asymptomatic?" showed that around 5\% to $80 \%$ of COVID-19 patients are asymptomatic cases ${ }^{15}$. Our findings differed slightly showing that $97.1 \%$ of the cases were asymptomatic.

In regards to the clinical characteristics of symptomatic patients, similar research published by Kayina et al on the clinical characteristics of COVID-19 in a tertiary care teaching hospital in India showed that $68.1 \%$ of the patients showed Fever as a symptom and $59.6 \%$ showed cough as a symptom. ${ }^{16}$ Our findings showed that $90.6 \%$ of all symptomatic patients showed a combination of both fever and cough as a symptom while presenting to the fever clinic.

From the present study, we have learnt that young males account for the most affected age group in Mid-Western Nepal. Individuals living in urban areas like Ghorahi, Tulsipur and Lamahi had a high incidence of COVID-19 infections as compared to rural municipalities, and districts bordering India also showed a higher incidence of COVID-19 infections as compared to the districts that don't border India. A majority of the patients presenting to 
the Fever Clinic are asymptomatic, and in those patients who are symptomatic, a combination of fever and cough were the chief clinical features.

\section{CONCLUSIONS}

With young adults being the most commonly affected age group, and males having a higher incidence of COVID-19 in MidWestern Nepal, it is important to carry out age-group targeted testing between ages 15 to 45 as it can help in flattening the infection curve. Alongside, contact tracing of quarantined individuals especially those with a significant travel history must be conducted. Since most patients were asymptomatic and typical presentations were fever and cough we need to focus on testing irrespective of the patient's clinical characteristics. As the incidence of COVID-19 increases in Mid-Western Nepal and Nepal in general, the government needs to carry out more tests in general, initiate public health programmes especially for comorbid patients, build more COVID-19 dedicated hospitals with ICU beds and ventilators. Hand hygiene, masking, maintenance of social distancing and an increase in testing is required to overcome this public health emergency.

\section{Acknowledgements}

We would like to thank the Department of Laboratory Medicine, IT department, faculties, administrative assistants for their support. Furthermore, we would like to thank the Fever clinic and RT-PCR laboratory team for making this research possible.

\section{REFERENCES}

1. Yesudhas D, Srivastava A, Gromiha M. COVID-19 outbreak: history, mechanism, transmission, structural studies and therapeutics. Infection. 2021;49:199-213. Crossref

2. WHO Coronavirus Disease (COVID-19) Dashboard [Internet]. Covid19.who.int. 2021 [cited 3 February 2021]. Available from: Website

3. The Lancet Respiratory Medicine. COVID-19 transmission-up in the air. The Lancet Respiratory Medicine. 2020;8(12):1159. Crossref

4. WHO Director-General's opening remarks at the media briefing on COVID-19 - 11 March 2020 [Internet]. Who.int. 2021 [cited 3 February 2021]. Available from: Website

5. Coronavirus disease 2019 (COVID-19) - Symptoms and causes [Internet]. Mayo Clinic. 2021 [cited 3 February 2021]. Available from: Website

6. CoVid19-Dashboard [Internet]. Covid19.mohp.gov.np. 2021 [cited 3 February 2021]. Available from: Website

7. COVID 19 - Active Cases, Deaths and Recovered [Internet]. Kathmandupost.com. 2021 [cited 3 February 2021]. Available from:Website

8. Kopel J, Perisetti A, Roghani A, Aziz M, Gajendran M, Goyal H. Racial and Gender-Based Differences in COVID-19. Frontiers in Public Health. 2020;8:418. $\underline{\text { Crossref }}$

9. Bienvenu L, Noonan J, Wang X, Peter K. Higher mortality of COVID-19 in males: sex differences in immune response and cardiovascular comorbidities. Cardiovascular Research. 2020;116(14):2197-206. Crossref

\section{Author Contributions:}

SSK, BL, PSB and SB conceived the study. SSK, PSB, BL, SSK, NR and UMSB designed the study. DS, BKA, PK, SKC, SS, SK, SP, AK, JL, SSK, were involved in the acquisition of the data. SSK and SSK did the analysis and interpreted the results
10. Situation update \#9- Corona virus disease 2019 (COVID-19) WHO country office for Nepal. 24th June 2020 [Internet]. Who.int. 2021 [cited 3 February 2021]. Available from: Website

11. Venkatesan P. The changing demographics of COVID-19. THE LANCET Respiratory Medicine 2020;8: E95. Crossref

12. COVID-19 cases by age group and sex. Australian Government Department of Health. 2020 [cited 3 February 2021]. Available from: Website

13. Upadhyay R, Chatterjee S, Saha S, Azad R. Age-group-targeted testing for COVID-19 as a new prevention strategy. Nonlinear Dynamics. 2020;101(3):1921-32. $\underline{\text { Crossref }}$

14. Policy Brief: COVID-19 in an Urban World. United Nations; 2020 [cited 3 February 2021]. Available from: Website

15. Heneghan C, Brassey J, Jefferson T. COVID-19: What proportion are asymptomatic? The Centre for Evidence-Based Medicine. 2020 [cited 3 February 2021]. Available from: Website

16. Kayina CA, Haritha D, Soni L, Behera S, Nair PR, Gouri M, et al. Epidemiological \& clinical characteristics \& early outcome of COVID-19 patients in a tertiary care teaching hospital in India: A preliminary analysis. Indian J Med Res. 2020;152(1 \& 2):100-4. Crossref

in collaboration with NR and UMSB. SSK and SSK wrote the first draft of the report. BL, PSB, SB, SP, AK, and JL supervised. SSK, SSK, PSB, BL, SB and PK critically revised the report for important intellectual content and approved the final version. 